\title{
EL FANTASMA DE EROS: AURA DE CARLOS FUENTES
}

\section{MARÍA C. AlBin*}

\section{RESUMEN}

Este trabajo propone una nueva lectura de la novela Aura de Carlos Fuentes, a partir de la concepción medieval del amor como una experiencia fantasmática. En la cultura de la Edad Media, el espectro emerge como origen y objeto de amor mostrando el estrecho vínculo que existe entre el deseo erótico y el fantasma. El fantasma de Eros se representa como el objeto inasible e incorpóreo del deseo, pues remite hacia algo que en realidad nunca se puede poseer. En la novela, Fuentes recrea el carácter fantasmagórico del amor a través del personaje femenino de Aura. La joven, cuya belleza inasible se constituye en su fuerza de seducción, encarna el fantasma de Eros. En el transcurso del relato se dan tres encuentros eróticos en los que se consuma la unión carnal de los amantes: la primera unión carnal representa el erotismo de los cuerpos, el segundo encuentro se puede describir como el erotismo de lo sagrado y el tercer y último encuentro se constituye en la epifanía de lo inasible.

Palabrasclave: Carlos Fuentes, Aura, novela mexicana, erotismo, fantasma, Eros, género, crítica espectral.

\section{ABSTRACT}

This work proposes a new reading of the novel Aura by Carlos Fuentes. Such an approach is based upon the medieval conception of the phantasmatic character of love. In the culture of the Middle Ages, the phantasm emerges as the origin and object of love. Therefore, the novelty of the medieval conception of Eros is precisely that it discovers

* Doctora en Literatura por la Universidad de Yale. Profesora del Departamento de Estudios Latinoamericanos e Ibéricos de la Universidad de Richmond en Virginia, EE.UU. Es autora del libro Género, poesía y esfera pública. Gertrudis Gómez de Avellaneda y la tradición romántica (Madrid: Trotta, 2002).E-mail: calbin@richmond.edu 
the link that exists between desire and the spectre. In his novel, Fuentes depicts the experience of love as a phantasmatic process through the feminine character of Aura. The unattainable beauty of the young woman, who represents the phantasm of Eros, constitutes the source of her seductive power. As the narration unfolds, three erotic encounters take place between the lovers: the first can be described as the eroticism of the bodies, the second as the eroticism of the sacred, and the last meeting as the epiphany of the unattainable.

Keywords: Carlos Fuentes, Aura, mexican novel, erotism, phantasm, Eros, gender, spectral criticism.

Recibido: 04.04.2006. Aceptado: 11.10.2006.

$\mathrm{E}$

N ESTE trabajo ofrecemos una nueva lectura de la novela Aura, una de las primeras obras de Carlos Fuentes que por su complejidad y riqueza ha sido y es producto de múltiples interpretaciones, las cuales se complementan entre sí ${ }^{1}$. La lectura del texto que proponemos se da a partir de la concepción medieval del amor que se basa en el descubrimiento de la irrealidad del mismo, es decir, del carácter fantasmático del proceso amoroso (Agamben, 2001: 148)2 . Por otro lado, la concepción del amor como proceso fantasmático lleva hasta las últimas consecuencias la conexión que se da entre el deseo y el fantasma, y según aclara Giorgio Agamben es ahí donde radica la novedad del concepto medieval del eros (Agamben, 2001: 148). El crítico sostiene que sólo en la cultura medieval emerge en primer plano el espectro como origen y objeto de amor, y concluye que a partir de ese instante "la situación propia del eros se desplaza de la visión a la fantasía”, la cual imagina los fantasmas en ausencia del objeto del deseo (Agamben, 2001: 148). En la doctrina que hace del fantasma origen de la experiencia amorosa está implícita la idea de que el espectro como verdadero objeto del amor habita en la imaginación del individuo que se enamora de una imagen (amar por sombra o por figura quiere decir que toda intención erótica está dirigida idolátricamente a una ymage) e intenta apropiarse de ella como si fuera una criatura que pertenece al ámbito de lo real (Agamben, 2001: 151). El gesto de la apropiación de la irrealidad se encuentra íntimamente

\footnotetext{
${ }^{1}$ En su estudio sobre la obra de Fuentes, Julio Ortega llega a la conclusión de que: "Son Aura, Cumpleaños y Una familia lejana sus novelas más persuasivas porque en ellas, como en una pieza musical barroca, el artificio y la poesía se funden con la autoridad de una forma compleja, en sí misma suficiente... Mito, historia, identidad, no son categorías dadas que permitan un mero seguimiento de sus variantes en cada novela. Ocurren como una retórica, en primer lugar, donde el yo basa sus referentes que, en el proceso del relato, son puestos en duda o rehechos" (47).

${ }^{2}$ Para un estudio de la tradición medieval del fantasma y la experiencia amorosa véase el reciente estudio de Ricardo Castells titulado Fernando deRojasand theRenaissanceVision: Phantasm, Melancholy, and Didacticism in Celestina (2000).
} 
vinculado a la alternancia y confusión entre sueño y vigilia que puede permear el proceso de enamoramiento como es el caso de la historia de amor que se narra en Aura. En otras palabras, el estado onírico altera y tergiversa la realidad, ya que el sueño contamina el ámbito de lo real.

En Aura, Fuentes recrea el carácter fantasmático de la experiencia amorosa que vincula con el proceso melancólico que resulta de la pérdida a través de la muerte del objeto de amor, el cual culmina en el fantasma del deseo que encarna el personaje que da nombre a la novela y que desempeña una función mediadora, pues une a los amantes desafiando el tiempo y la condición de su propia mortalidad. En esta perspectiva la muerte del ser amado genera un estado de melancolía que se asocia a un proceso erótico que establece un comercio ambiguo con los fantasmas del deseo-Aura-Consuelo. En dicho proceso lo que es real pierde su realidad y es suplantado por lo irreal que experimenta una transformación hasta ocupar la categoría de lo real, es decir, ante la pérdida del objeto de amor, el amante o la amante convertido en sujeto melancólico reacciona negando el mundo externo y se refugia en una psicosis alucinatoria del deseo. En el texto de Fuentes el espacio exterior está representado por la ciudad y sus ruidos disonantes que insinúan la fragmentación que padece el individuo ante la vida acelerada de la urbe moderna, ya que el ser íntimo se percata de que afuera todo es desmedido y todo se desborda. En el instante de traspasar el umbral de la vieja casona de Consuelo, ubicada en la parte antigua de la ciudad, el narrador nos dice que: "La puerta cede al empuje levísimo, de tus dedos, y antes de entrar miras por última vez sobre tu hombro, frunces el ceño porque la larga fila detenida de camiones y autos gruñe, pita, suelta el humo insano de su prisa. Tratas, inútilmente de retener una sola imagen de ese mundo exterior indiferenciado" (13-14). La dialéctica que se establece entre lo de adentro y lo de afuera, entre el espacio interior de la casa y el espacio exterior de la ciudad, se indica con la puerta que sugiere lo entreabierto y que se convierte en emblema de la vacilación del ser que confronta lo cerrado y lo abierto. Ante la confrontación de los espacios, Felipe Montero, el joven historiador, opta por la negación del ámbito externo, lo cual a su vez propicia que se le adjudique al espectro del deseo un principio de realidad que lo ubica en una dimensión nueva y fundamental (Agamben, 2001: 63) 3 $^{3}$ Por otra parte, la naturaleza del fantasma de eros se caracteriza por una doble polaridad, pues oscila entre un carácter demoníaco-mágico y una identidad angelical y contemplativa (Agamben, 2001: 61). Esta dualidad o doble naturaleza que distingue al espectro del deseo se hace evidente en las palabras

\footnotetext{
${ }^{3}$ Para una explicación de la dialéctica entre lo de adentro y lo de afuera se puede consultar el ensayo de Gastón Bachelard que lleva el mismo título y que aparece en el libro La poética del espacio.
}

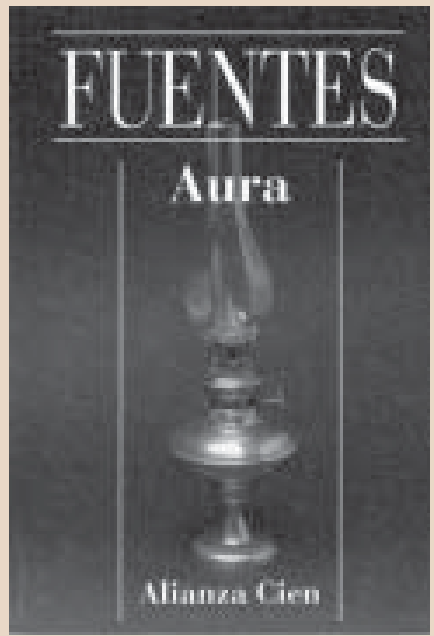


con que el General Llorente concluye sus M emorias: "Consuelo, también el demonio fue un ángel, antes", las cuales se refieren a la dualidad del temperamento de su esposa, quien actúa como mujer devota y hechicera al mismo tiempo (57).

La aparición de Aura en la ventana de la casa desencadena la experiencia erótica que guía el relato de principio a fin, y de ese modo se da la convergencia entre el fantasma y Eros, en cuanto el deseo tiene como origen y objeto inmediato la figura fantasmagórica de la joven que contempla Felipe desde la ventana: "de la cual se retira alguien en cuanto tú la miras"(13). Esta breve escena que marca el encuentro inicial entre los amantes sugiere la imposibilidad de cruzarse con la mirada de ese "alguien" que aparece de repente, y que da la impresión de ser "algo" en huida o fuga que sobrepasa la percepción visual, y que nos remite a la dimensión errante del fantasma siguiendo la tradición platónica que presenta las figuras de las almas de los muertos vagando y persiguiendo a los vivos. Al espectro se le adjudica el poder incomparable de ver sin ser visto, pues sólo es descubierto por Felipe en un breve instante y de ahí que entre sus cualidades se encuentren esa "furtiva visibilidad de lo invisible", es decir, el no estar al alcance de la vista, ya que puede ser invisible, inaudible e intangible (Derrida, 1994: 7). Como se puede apreciar, el relato de amor que se narra comienza con la aparición de un espectro y prosigue con la inminencia de su regreso, pues Consuelo le dice al joven historiador que aguarda el retorno de su sobrina y compañera, quien es descrita en términos fantasmáticos dejando implícito que desempeña una función mediadora porque entre "la mujer y tú se extiende otra mano que toca los dedos de la anciana. Miras a un lado y la muchacha está allí, esa muchacha que no alcanzas a ver de cuerpo entero porque está tan cerca de ti y su aparición fue imprevista, sin ningún ruido...” (19).

En el siguiente pasaje, la génesis del amor se describe en términos fantasmáticos y se destaca que este sentimiento nace de la mirada, es decir, de la fascinación a través de los ojos verdes de Aura, a los que se les adjudica un cierto poder de transformación y una fuerza seductora que atrae a quien los contempla: "Al fin, podrás ver esos ojos de mar que fluyen, se hacen espuma, vuelven a la calma verde, vuelven a inflamarse como una ola: tú los ves y te repites que no es cierto, que son unos hermosos ojos, verdes... Sin embargo, no te engañas: esos ojos fluyen, se transforman, como si te ofrecieran un paisaje que sólo tú puedes adivinar y desear" (20). Esa mirada del espectro que lo seduce se convierte en un espíritu sutil que penetra a través de la visión y le brinda una imagen de la amada, cuyos contornos no se pueden precisar ni fijar en la memoria. Sin embargo, desata el impulso erótico al estar implícita la pérdida de control hasta el punto de que el enamorado llega a creer que puede apropiarse de la imagen como si fuera una criatura real: "y tú desvías una y otra vez la mirada para que Aura no te sorprenda en esa impudicia hipnótica que no puedes controlar. Quieres, 
aún entonces, fijar las facciones de la muchacha en tu mente. Cada vez que desvíes la mirada, las habrás olvidado ya y una urgencia impostergable te obligará a mirarla de nuevo", y más adelante se nos dice que Aura "al fin levanta la mirada y tú vuelves a dudar de tus sentidos, atribuyes al vino el aturdimiento, el mareo que te producen esos ojos verdes, limpios, brillantes, y te pones de pie, detrás de Aura, acariciando el respaldo de madera de la silla gótica, sin atreverte a tocar los hombros desnudos de la muchacha, la cabeza que se mantiene inmóvil. Haces un esfuerzo para contenerte" (2526). Felipe anticipa la liberación de la sensualidad que lo aguarda y la plenitud del disfrute erótico, pues reflexiona ante la influencia que ejercen sobre él los ojos de la joven, pues confiesa sentirse "invadido por un placer que jamás has conocido..., pero que sólo ahora experimentas plenamente, liberándolo" (26).

En la escena anterior de marcado acento erótico, la referencia a los hombros desnudos y la cabeza de Aura indica que el fantasma se está formando: el espectro está cobrando forma, ya que el historiador comienza a percibir lo invisible en un gesto paradójico de ver sin ver, e incluso piensa en el cuerpo no corpóreo ( (Derrida, 1994: 149). El pasaje citado alude a la encarnación o incorporación del fantasma que se define como el instante de transmutarse en carne, lo cual implica que el espectro se dota de un cuerpo. Al respecto, Derrida aclara que no existe un fantasma sin la apariencia de la carne en un espacio de una "visibilidad invisible", porque sólo es posible engendrar un fantasma dándole un cuerpo. El filósofo reitera que para convertirse en un espectro debe haber un regreso al cuerpo, pero explica que ese cuerpo prestado en vez de ser concreto resulta más abstracto que nunca, por lo que describe este proceso como una incorporación paradójica (126). Más adelante define el espectro como la aparición carnal del espíritu y alega que la materia fenoménica es su cuerpo caído y culpable, el cual se halla vinculado a la espera impaciente y nostálgica de una redención (136). En el texto de Fuentes, la resurrección de la carne y la salvación de Aura-Consuelo se cumple a través de la unión carnal de los amantes, gesto que anula la temporalidad cotidiana y desafía la muerte, pues se alcanza un renacimiento o una renovación continua a partir de la experiencia amorosa.

Por otro lado, la mirada del espectro también se manifiesta en el poder hipnótico que la anciana Consuelo ejerce a través de sus ojos sobre el historiador: "La señora tratará de retener tu atención: te mirará de frente para que tú la mires, ... tú debes de hacer un esfuerzo para desprenderte de esa mirada -otra vez abierta, clara, amarilla, despojada de los velos y arrugas que normalmente la cubren- y fijar la tuya en Aura, que a su vez mira fijamente hacia un punto perdido..." (35). La ley de esta doble mirada que posee la capacidad de transformarse es, por un lado, sentir que el fantasma nos mira y que al cruzarnos con su mirada hay que someterse a su voz: la voz

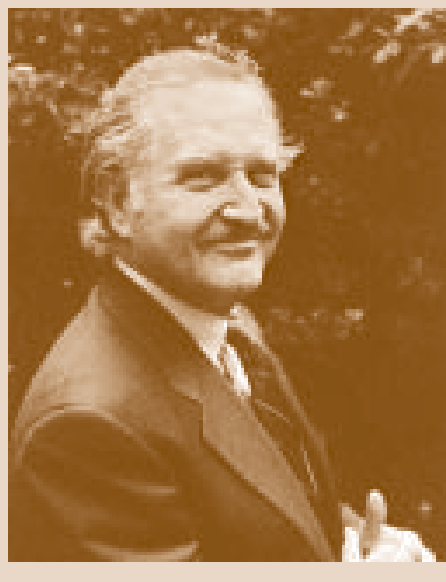

C. Fuentes 
aguda y cascada de la anciana que en ocasiones es descrita como un murmullo y la campana de Aura, cuyo sonido no sólo anuncia la comida, sino que sugiere una convocación ritual (14). Por un lado, la mirada del fantasma nos remite al secreto de su origen, es decir, a la identidad problemática del espectro, que es ella misma (la tía anciana) y la otra (su sobrina joven), y por otro, revela que en la mayor parte de los casos no podemos ver al espectro que nos observa, quien detenta el poder de ver sin ser visto o que, como ocurre con la aparición de Aura, el fantasma tienta a Felipe a seguir su mirada, esto es, parece decir que siga la mirada del espectro, pero de inmediato desaparece suscitando en el individuo un sentimiento de nostalgia que lo invade y que se asocia a la pérdida del objeto de amor. Felipe se percata de que la fuerza de atracción que emana la joven, esa pasión de seducción que permea sus movimientos, hace que él anhele seguir sus pasos, pero al mismo tiempo está consciente de que no la sigue con la vista, "sino con el oído: sigues el susurro de la falda, el crujido de una tafeta -y estás ansiando ya, mirar nuevamente esos ojos" (21). Sin embargo, Aura se aleja sin que él pueda contemplar su rostro una vez más (21). El misterio del rostro de la joven implica que la seducción adquiere la forma de un enigma, ya que el secreto no es revelado y de ahí es precisamente que deriva toda su fuerza, su poder de fascinación y de intercambio alusivo y ritual (Baudrillard, 1977: 77).

El motivo de la vuelta o del regreso del espectro es de suma importancia en la novela, pues se encuentra vinculado al fantasma de Aura y a la espera de su aparición. Por primera vez, el vocablo "volverá" se emplea en el texto para aludir a la ausencia de Saga, la coneja que es la compañía de la viuda, quien afirma en un diálogo con Felipe que el animal va a regresar; y de inmediato, el narrador destaca la relevancia del concepto del retorno que vincula al acto de conjurar, es decir, de hacer aparecer o volver, cuando declara "pero esa palabra -volverá- vuelves a escucharla como si la anciana la estuviese pronunciando en ese momento" (18). Más adelante, en el pasaje en que la anciana se dirige al joven historiador para reiterar que, según le había informado antes, “-Aura. Mi compañera. Mi sobrina.” Había regresado (19), vemos cómo el tema recurrente de la vuelta está vinculado al de la espera, ya que Consuelo insinúa la inminencia de la reaparición de Aura, porque tanto ella como Felipe aguardan el regreso del espectro. El retorno esperado del fantasma se repite una y otra vez en el transcurso del relato e indica que la reaparición de la joven se convierte en una obsesión para Felipe, quien incluso experimenta una falta de interés paulatina en su trabajo, ya que deja de prestar atención a la tarea de revisar las memorias del General Llorente: "Allí leerás los nuevos papeles, la continuación, las fechas de un siglo en agonía... Las hojas amarillas se quiebran bajo tu tacto; ya no las respetas, ya sólo buscas la nueva aparición de la mujer de ojos verdes:" (56). Para el historiador el aguardar la reaparición del fantasma se constituye en 
su única motivación, ya que Aura se ha transformado en un espectro de seducción que lo obsesiona. La seducción es precisamente lo que desvía al historiador de su deseo de llevar a cabo una obra totalizadora: "podrías pasar cerca de un año dedicado a tu propia obra, aplazada, casi olvidada. Tu gran obra de conjunto sobre los descubrimientos y conquistas españolas en América. Una obra que resuma todas las crónicas dispersas, las haga inteligibles, encuentre las correspondencias entre todas las empresas y aventuras del siglo de oro, entre los prototipos humanos y el hecho mayor del Renacimiento" (33). Baudrillard explica que el acto de ser seducido equivale a ser desviado de su verdad, de ahí que en la novela la seducción del espectro aparte al otro, es decir, a Felipe de su objetivo inicial de escribir una obra maestra que finalmente abandona (Baudrillard, 1997: 79).

El historiador está consciente de que no posee el control sobre las idas y venidas del espectro, ya que la partida y el regreso de Aura es un asunto de la repetición que sólo Consuelo domina porque es ella quien posee la fuerza secreta: el poder de traer con la voz o convocar un espíritu. Durante una conversación entre la viuda y Felipe, previa a una escena de amor, el joven expresa la esperanza de que el fantasma de Aura regrese: "Ella puede regresar en cualquier momento..." (60). El historiador aguarda el retorno del espectro que Consuelo puede convocar, pero ella misma le confiesa que la joven no volverá porque: “-Estoy agotada. Ella ya se agotó. Nunca he podido mantenerla a mi lado más de tres días” (61). A través de una especie de encantamiento mágico, la anciana conjura la presencia de la sobrina y hace que aparezca en el instante de la evocación aquello que no estaba ahí. El General cuenta en sus manuscritos que una vez halló a su esposa gritando: "Sí, sí, sí , he podido: la he encarnado; puedo convocarla, puedo darle vida con mi vida" (57). Por lo tanto, siguiendo la confesión de la propia Consuelo, Aura se constituye en un doble del fantasma de la tía, esto es, la sobrina es un fantasma del fantasma, lo cual implica que es una encarnación que posee un cuerpo prestado en un intento de reapropiarse de la vida. Para entender lo corpóreo del fantasma es necesario tener en cuenta que el espectro tiene un cuerpo, pero sin propiedad y que el cuerpo fantasmagórico de Aura resulta un simulacro porque es el cuerpo de alguien, es decir, de Consuelo, como si fuera otro -su joven sobrina que envejece en el transcurso de la narración pasando por las etapas de niña, mujer madura y anciana, las cuales coinciden con los tres encuentros eróticos de los amantes.

Por otro lado, ese "algo" que se hace presente al ser conjurado es difícil de nombrar, pues no es ni alma ni cuerpo, y al mismo tiempo es una y el otro, es decir, simultáneamente es ambos. Además el estar ahí del ausente, aquel que ha partido de esta vida se convierte en "algo" innombrable, ya que Felipe no sabe con certeza si las dos mujeres están vivas o muertas, o si una es el doble de la otra, lo cual implicaría que la joven y la anciana son la misma persona. Felipe medita acerca de la relación entre la tía y la sobrina, quienes

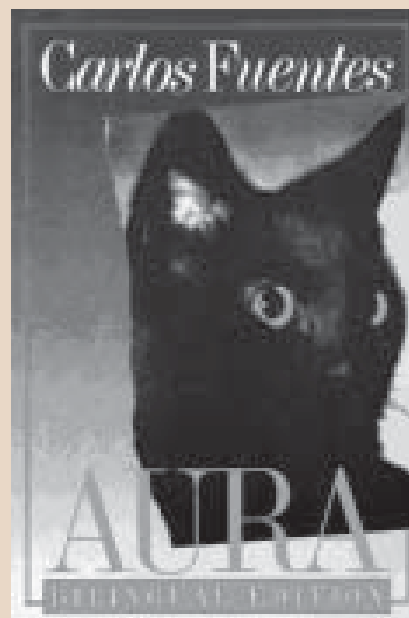


actúan de forma simultánea cuando están juntas porque "hacen exactamente lo mismo: se abrazan, sonríen, comen, hablan, entran, salen, al mismo tiempo, como si una imitara a la otra, como si de la voluntad de una dependiese la existencia de la otra" (52). El historiador intenta descartar dicha reflexión murmurando los nombres de los objetos que ve en el botiquín, ya que éstos representan la realidad de la vida cotidiana que se contrapone a las dos mujeres que pertenecen a otro mundo: al ámbito de lo sobrenatural o el mundo de los muertos. Felipe se aferra a los objetos "para olvidar lo otro, lo otro sin nombre, sin marca, sin consistencia racional” (52). Por otro lado, el joven historiador es asediado por lo mismo (Aura-Consuelo) y por lo otro (tía y sobrina), por lo mismo que cada vez es otro, y de ahí que la identidad del fantasma o el simulacro de su identidad se constituya en uno de los problemas centrales del texto.

La oposición entre presencia y ausencia -lo que está y lo que no estárige la vuelta y reaparición del fantasma asociada al movimiento de su partida y de su llegada, el cual crea el tiempo de su regreso: el eterno retorno. Esa temporalidad se puede describir como totalizadora, pues comprende el pasado que se asocia al mundo de los muertos, el presente que se asocia a la vida y el futuro. Las idas y venidas del espectro se organizan en torno a los tres niveles temporales: el fantasma viene del pasado, en el momento de su aparición se ubica en el presente y remite al tiempo futuro con la esperanza o promesa de que vuelva, pues en palabras de Derrida, el espectro es el futuro porque es lo que va a venir (39).

El fantasma de Aura detenta la fuerza soberana de la seductora, esa fascinación extraña que Felipe experimenta cuando se percata de su aparición. El secreto y la fuerza de esa seducción fantasmagórica no se basa en la ausencia pura, sino en un eclipse de la presencia, cuya estrategia consiste en estar y no estar ahí. En otras palabras, el secreto del poder de seducción reside en la estética de la desaparición que nos remite a la intermitencia de la presencia: no estar allí donde se la cree, donde se la desee (Baudrillard, 1977: 83). Por ejemplo, en el tercer capítulo de la novela, el narrador nos dice que al escuchar el aviso de la campana que toca Aura para indicarle que el desayuno está listo, se asoma al corredor y trata de detenerla, pero la joven desciende por las escaleras por lo que decide seguirla "pero al llegar al vestíbulo ya no la encuentras" (31-32).

La "belleza inasible" de Aura se constituye en la fuerza de seducción, ya que el fantasma de Eros posee una capacidad de embrujo que se manifiesta como un poder de atracción y de distracción sobre el historiador, quien deja a un lado sus tareas según él mismo confiesa: "Permaneces allí, olvidado de los papeles amarillos, de tus propias cuartillas anotadas," pensando sólo en la joven (37). El espectro de Aura somete a Felipe a la intensidad del juego y del reto de la pasión de seducción, la cual se traduce en una fuerza de absorción y fascinación que culmina en un proceso de desafío y de muerte 
(Baudrillard, 1977: 79). El juego de la seductora consiste en decepcionar al otro al mismo tiempo que exalta el deseo de Felipe por medio de su aparición que va siempre acompañada de la inminencia de su desaparición (Baudrillard, 1977: 92). Esa característica o rasgo del juego de la seductora, el aparecer y desaparecer, también se relaciona con el poder que le brinda el estar ahí como "algo" inasequible. Antes de consumarse el primer encuentro erótico, el historiador es arrastrado hacia la imagen de la amada -el espectro de Aura-inscrita en la fantasía que adopta la forma del deseo que permanece fijo en lo que se muestra como "algo" inalcanzable (Agamben, 2001: 47). De ahí se deriva la contradicción interna que desencadena el impulso erótico como un gesto que quiere abrazar lo inasible y lo incorpóreo: Aura, el fantasma de eros (Agamben, 2001: 48).

En el transcurso del relato se dan tres encuentros amorosos en los que se consuma la unión carnal de los amantes, lo cuales coinciden, por un lado, con los tres folios de los manuscritos del General Llorente que la viuda le entrega a Felipe para su lectura y revisión y, por otro, con el ciclo de vida de la sobrina: niña, mujer madura y anciana.

El primer encuentro erótico entre Felipe y Aura se da cuando el historiador despierta de una pesadilla en la que sueña con la figura fantasmagórica de unas manos descarnadas que avanzan hacia él llevando una campana y con un "rostro de ojos vaciados" (37). Estas imágenes corporales de unas manos esqueléticas y de una faz que carece de ojos nos remiten al cadáver en descomposición de la anciana, y de ahí que esté implícito que Consuelo está muerta; incluso el propio Felipe alega que Consuelo "es una mujer vieja, casi un cadáver" (53). Pero en el acto amoroso, la imagen fantasmal que no se percibe en la totalidad de su cuerpo se transforma en el espectro de Eros que adopta la forma del cuerpo desnudo de la niña Aura. La sobrina despierta a Felipe de la pesadilla tomando la iniciativa del juego erótico al recorrer con sus besos el cuerpo entero del amante, quien no alcanza a "verla en la oscuridad de la noche sin estrellas", percatándose de su presencia sólo a través de los sentidos del olfato y del tacto, pues siente "en sus brazos la piel más suave y ansiosa" (37-38). Esta primera unión carnal representa el erotismo de los cuerpos en el que se destaca la desnudez "que se opone al estado cerrado, es decir, el estado de existencia discontinua" e intenta sustituir el aislamiento del ser por "un estado de comunicación que revela la busca de una continuidad posible del ser más allá del replegamiento sobre sî" (Bataille, 1998: 29, 31). De ahí que cualquier forma de erotismo esté gobernada por la

${ }^{4}$ Bataille define el erotismo como una experiencia interior, pues explica que: "El erotismo es uno de los aspectos de la vida interior del hombre. Nos equivocamos con él porque busca sin cesar afuera un objeto del deseo. Pero ese objeto responde a la interioridad del deseo"; y más adelante reitera que el erotismo humano "pone a la vida interior en cuestión", pues pone al ser en cuestión (Bataille, 1998: 45). 
nostalgia de la continuidad perdida, y busque la fusión, es decir, la superación del ser personal y el rebasar todo límite 4 . El encuentro erótico culmina en una especie de rito de iniciación que somete al amado a las reglas propias del juego de la seductora, cuya exigencia ritual sella un pacto entre los amantes. El poder de la seducción, esa fuerza soberana de una fascinación extraña que ejerce la mujer seductora, se manifiesta en el convenio que se sella entre los participantes de esta unión carnal, y que se resume en la aseveración de Aura que clausura la primera experiencia amorosa: "Eres mis esposo", a lo cual Felipe asiente (38).

El segundo encuentro amoroso entre Felipe y Aura se puede calificar como un erotismo de lo sagrado, ya que en la fusión carnal de los amantes convergen la intimidad sexual y lo religioso, y de esa forma se sacraliza el acto erótico. Una ceremonia ritual que nos remite a la Pasión de Cristo preside la unión de la pareja y el acto carnal se presenta como una ceremonia de comunión entre los participantes 5 . Por otra parte, la concepción del amor como proceso fantasmático relacionada con el acto de enamorarse por sombra, se puede apreciar en el siguiente pasaje que describe la atmósfera fantasmagórica que sirve de trasfondo a la unión de los amantes: "Sentado en la cama, tratas de distinguir el origen de esa luz difusa, opalina, que apenas te permite separar los objetos, la presencia de Aura, de la atmósfera dorada que los envuelve" (48). En las líneas anteriores se alude a Aura como al fantasma de Eros, cuya figura al igual que el contorno de los objetos que la rodean no es posible fijar a través de la percepción visual. Por otro lado, la luz opaca contribuye a crear el ambiente ambiguo y confuso entre el estado onírico y el de vigilia que enmarca la escena erótica, y que a la vez le otorga un sentido de irrealidad que resalta el aspecto fantasmático de la experiencia amorosa. Una vez consumado el acto carnal, Felipe advierte la presencia de la señora Consuelo en la habitación, pues nos dice: "Recostado, sin voluntad, piensas que la vieja ha estado todo el tiempo en la recámara"(50), y esta aparición de la anciana está relacionada con la identidad problemática del espectro del deseo, ya que en este punto del relato las figuras de las dos mujeres, tía y sobrina, comienzan a coincidir en un mismo espacio: la recámara de los amantes.

La imagen de un "gran crucifijo mexicano" que adorna la recámara preside la escena del acto amoroso, en el que Aura experimenta un cambio de la joven del primer encuentro erótico y se presenta como una mujer madura de más o menos cuarenta años de edad. Sin embargo, al igual que en el acto inicial es ella quien toma la iniciativa e impone sobre su amante las reglas

\footnotetext{
${ }^{5}$ Una posible intepretación del segundo encuentro erótico se basa en el ritual de la "Misa negra" que describe Jules Michelet en La sorciere. Para un análisis de la influencia del historiador francés en Aura véase el artículo de Ana María Alban de Viqueira: "Estudio sobre las fuentes de Aura de Carlos Fuentes” (Comunidad, México, II, 8, agosto de 1967).
} 
del juego erótico, pues le advierte a Felipe: "Vamos a jugar. Tú no hagas nada. Déjame hacerlo todo a mí" (47). El acto ritual de los amantes comienza con un lavatorio o purificación, en el que Aura le lava los pies a Felipe mientras dirige su mirada al Cristo de madera negra: "Tú sientes el agua tibia que baña tus plantas, las alivia", y continúa con una danza, un vals que bailan al ritmo de una melodía que ella susurra mientras desnuda al amado: "girando al ritmo lentísimo, solemne, que ella te impone. También tú murmuras esa canción sin letra, esa melodía que surge naturalmente de tu garganta: giran los dos, cada vez más cerca del lecho" (48). La ceremonia erótica termina con un acto de comunión similar al rito religioso de recibir los fieles la Eucaristía que se celebra durante la misa cristiana. En este sacramento del altar, mediante las palabras que el sacerdote pronuncia, el pan y el vino se transforman en el cuerpo y la sangre de Cristo. Aura oficia como sacerdote y consagra un "trozo de harina delgada" que coloca "contra los muslos cerrados", sobre los que quiebra la oblea y en un acto de comunión le ofrece a Felipe la mitad que "tú tomas, llevas a la boca al mismo tiempo que ella" (49). En este acto de consagración de la oblea, la mujer es quien se ofrece como alimento al amado, pues sobre su cuerpo desnudo con los "brazos abiertos, extendidos de un extremo al otro de la cama, igual que el Cristo negro" asume una postura de entrega total a Felipe: "Aura se abrirá como un altar" (49). A través de esta ceremonia, la pareja participa del misterio de la comunión que supone la unión de los amantes en un solo ser, pero también se establece un paralelismo entre el cuerpo de Aura y el de Cristo, ya que por medio de la consagración de la hostia se transforma en el cuerpo del Redentor. Por lo tanto, en esta escena convergen el sacrificio de la misa, es decir, la muerte de Cristo en la cruz y su resurrección, con el acto de amor humano, lo cual implica que a través del rito de la comunión los amantes se redimen. La salvación de ambos es la promesa de amor eterno que logra vencer la muerte al anular la temporalidad finita del acontecer humano. El encuentro erótico acaba con un pacto en el que Aura y Felipe se juran amor

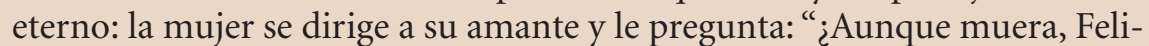
pe? ¿Me amarás siempre, aunque muera?", a lo que éste asiente diciendo: "Siempre, siempre. Te lo juro. Nada puede separarme de ti" (49).

Después del segundo encuentro erótico, Felipe se siente embargado por una tristeza vaga y profunda que le causa la separación del objeto de amor, pues confiesa: "Duermes cansado, insatisfecho. Ya en el sueño sentiste esa vaga melancolía, esa opresión en el diafragma, esa tristeza que no se deja apresar por tu imaginación. Dueño de la recámara de Aura, duermes en la soledad, lejos del cuerpo que creerás haber poseído" (51). Con su alusión a la lejanía de Aura, el historiador expresa la soledad del amante que está desunido o separado de la persona amada, lo cual le produce un estado de melancolía que se asocia a la pérdida del objeto de amor. Sin embargo, la melancolía no es tanto una reacción ante la pérdida del objeto erótico, ya que

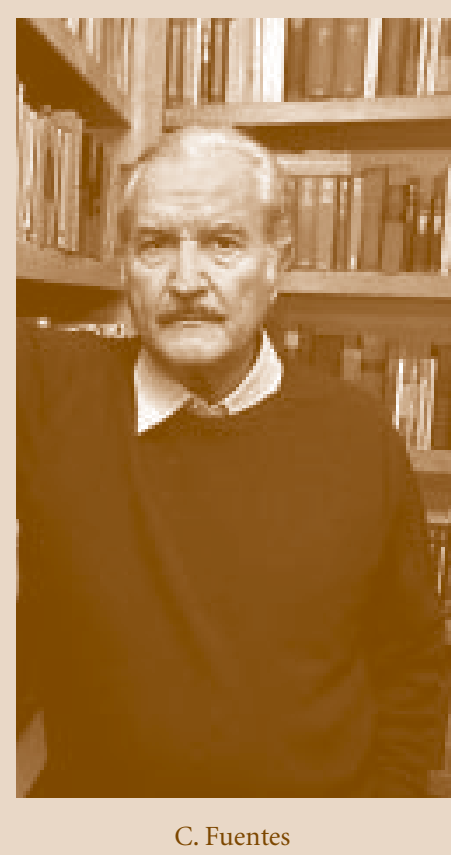


escenifica la simulación que consiste en "la capacidad fantasmática de hacer aparecer como perdido un objeto inapropiable" (Agamben, 2001: 53). El objeto inasible, este fantasma de Eros que encarna Aura, en cuanto presencia de una ausencia es inmaterial e intangible, pues constantemente remite más allá de sí mismo hacia algo que en realidad nunca se puede poseer (Agamben, 2001: 72). Cuando Felipe descubre su verdadera identidad, "su verdadera faz", el rostro del General Llorente, también llega a la conclusión de que ya no le "será posible tomar entre las manos ese polvo sin cuerpo" (59). Sin embargo, el estado melancólico en que se halla Felipe es lo que hace posible una apropiación en una circunstancia en la que ninguna posesión es posible en realidad. La melancolía que sufre el historiador le permite poseer al objeto del deseo -el fantasma de Eros - sólo en la medida en que afirma su pérdida. La estrategia que adopta, en tanto sujeto melancólico, es dejar abierto un espacio a la existencia de lo irreal que implica entrar en una escena en la que el individuo puede establecer una relación con el objeto inasible, es decir, con el fantasma de Eros, e intentar una apropiación del espectro (Agamben, 2001: 53-54).

La sacralización del acto amoroso, esto es, la unión sexual en tanto comunión, que se da en el segundo encuentro entre los amantes, brinda a Felipe un conocimiento superior de sí mismo y de la dimensión temporal de la existencia humana. Dicha comunión tiene el poder de hacer sensible una identidad profunda que antes del acto erótico se hallaba oculta, pues Felipe examina unos antiguos retratos y en la tercera foto ve a Aura y al General sentados juntos en un banco y llega a la conclusión de que "Aura no se verá tan joven como en la primera fotografía, pero es ella, es él, es... eres tú" (58). El historiador descubre que él es idéntico al difunto General Llorente, pues sus facciones son las mismas y que su verdadera identidad pertenece al otro, y ahora a través de la vía amorosa o la fusión de los amantes, puede abandonar la máscara y reemplazarla con "tu verdadera faz, tu rostro antiguo" (59). Por medio de la unión amorosa, también adquiere un conocimiento relacionado con la dimensión temporal de la existencia en que descarta el tiempo cronológico y pasa a habitar la temporalidad auténtica, pues reflexiona en torno a este asunto cuando declara: "No volverás a mirar tu reloj, ese objeto inservible que mide falsamente un tiempo acordado a la vanidad humana, esas manecillas que marcan tediosamente las largas horas inventadas para engañar el verdadero tiempo" (59).

El tercer y último encuentro erótico se constituye en la epifanía de lo inasible, que se puede definir como la apropiación de lo que debe permanecer inapropiable. El gesto de apropiarse de lo que es inasequible, en particular, nos referimos al intento de asir lo que está muerto, es precisamente lo que requiere la fuerza más grande, incluso el poder de la magia (Agamben, 2001: 14). En su condición de viuda, la anciana asume la postura del sujeto melancólico que experimenta una rebeldía ante la pérdida del objeto de amor 
debido a la muerte del General Llorente. Pero su rebeldía llega hasta el punto de esquivar el acontecimiento de la muerte del esposo, aferrándose al objeto perdido, y de negar la posibilidad de su propia muerte, pues en su psicosis alucinatoria del deseo la seductora se cree inmortal y eternamente joven. Las memorias del difunto general revelan el ansia de eterna juventud de Consuelo y su obsesión con la belleza imperecedera. El general revela que su esposa poseía un conocimiento oculto al que llegó a través de la magia, que le permitía reencarnar en su imagen juvenil, pues en los manuscritos menciona el uso de brebajes y el cultivo de plantas que le daban el dominio de un poder extraño, y además alude a los sacrificios de animales, víctimas inmoladas que incitaban al amor (57). Consuelo se vale de la magia para propiciar sus encuentros eróticos y descubrir a su marido muerto en la reencarnación del historiador, a quien atrae con sus poderes de hechicera.

Con el último acto de amor se resuelve el dilema de la pérdida/posesión que se presenta a lo largo del relato: la unión carnal de los amantes que clausura el texto es capaz de convertir la separación o privación, es decir, la ausencia del objeto de amor, en una segunda adquisición, pero ahora esa posesión es interior y más intensa porque desafía el tiempo cronológico y logra vencer la muerte. El acto carnal se erige en una aprobación de la vida hasta en la muerte porque la actividad erótica representa la exuberancia de la vida, ya que a través de la fusión los cuerpos se abren a un sentimiento de continuidad profunda (Bataille, 1998: 23, 31). La misma Aura le enseña a Felipe que la verdad de la vida se revela en la muerte cuando le dice: "Hay que morir antes de renacer...", lo cual sugiere que el tiempo cronológico se anula y en su lugar se instaura la eterna repetición cíclica que permite una cadena de reencarnaciones en que los amantes se podrán encontrar (53).

Felipe ama a una mujer radicalmente separada de él, al fantasma de Eros que le precede a la tumba, ya que aunque al principio no lo sabía AuraConsuelo ya estaba muerta ${ }^{6}$. Sin embargo, el espectro del deseo se convierte

${ }^{6} \mathrm{Al}$ respecto comenta el propio Fuentes:

"En una de mis novelas, Aura, quise hacer explícita esta cadena genésica del mito. La situación de dos mujeres, una joven y otra anciana, en relación con un joven extranjero, proviene, próximamente, de un árbol genealógico de la narrativa europea del siglo pasado: Miss Bourderau, Tina y el Narrador en LospapelesdeA spern de James; Miss Havisham, Stella y Pip en Lasgrandes esperanzas de Dickens; y la Condesa, la joven Lizveta y Hermann en Pikova Dama de Pushkin. En Pushkin, Dickens y James, el hombre atrae a la mujer en contra de la anciana. En mi variación del mito, las dos mujeres se mantienen aliadas contra el hombre. Es más: las dos mujeres son la misma, la vieja capaz de evocar su propia juventud. Pero esta dimensión del mito proviene, a su vez, del cuento japonés de Akinari, escrito en el siglo XVIII, La casa entre los juncos, en el que la mujer muerta reaparece con su voz joven en el cuerpo de una anciana. Pero el cuento de Akinari (y la película de Mizoguchi, U getsu M onogatari, basada en aquél), provienen de los cuentos japoneses del Togii Boko (1666) y éstos de la colección, antiquísima, de cuentos chinos, Tsien teng sin boa, que contiene un relato básicamente idéntico al de Aura" ("Juan Rulfo: el tiempo del mito", 1990: 153-54). 
en una obsesión para él hasta el punto que ama y sueña a la mujer, quien finalmente lo invita a reconocerse en la muerte. El tercer encuentro amoroso entre los amantes ocurre cuando Felipe se convierte en la reencarnación del General Llorente, y de esa forma llega a conocer y a amar a Aura-Consuelo viviendo la experiencia erótica como una aprobación de la vida hasta en la muerte (Bataille, 1998: 23). La unión de los amantes hace evidente que la muerte es signo de vida, pues se muestra como una abertura a lo ilimitado y se traduce en la posibilidad de una renovación incesante o de un eterno retorno.

El acto carnal en tanto comunión entre los participantes sella un pacto de amor eterno, el cual otorga a los amantes el derecho de regresar vivos porque la resurrección de la carne, esto es, de los amantes en tanto seres corporales, implica que los cuerpos resucitados regresarán a las almas en un ciclo de renovación incesante. En el siguiente pasaje, el retorno de la muerte se hace posible en el instante del acto erótico, ya que los amantes celebran la unión inefable entre lo corpóreo y lo incorpóreo, entre el alma y el cuerpo, y en la experiencia amorosa se anula el devenir temporal para instaurar el eterno presente: "verás bajo la luz de la luna el cuerpo desnudo de la vieja, de la señora Consuelo, flojo, rasgado, pequeño y antiguo, temblando ligeramente porque tú lo tocas, tú lo amas, tú has regresado también..." (62). El resultado de esta última experiencia erótica es que quedan abolidos y confundidos las fronteras espaciales entre lo exterior y lo interior; los límites temporales entre pasado, presente y futuro que se funden en el eterno presente; lo corpóreo y lo incorpóreo y el deseo y su objeto: el fantasma de Eros.

\section{REFERENCIAS}

Agamben, Giorgio. 2001. Estancias. La palabra y el fantasma en la cultura occidental. Trad. Tomás Segovia. Valencia: Pre-textos. Stanze. La parola eil Fantasma nella cultura occidentale. Torino: Giulio Einaudi editore s.p.a., 1977.

Alazraki, Jaime. 1982. "Theme and System in Carlos Fuentes' Aura”. CarlosFuentes: A Critical View. Ed. Brody, Robert y Charles Rossman. Austin, Texas: University of Texas Press, 95-105.

Albán de Viqueira, Ana María. 1967. "Estudio de las fuentes de Aura de Carlos Fuentes”. Comunidad (México), agosto: 396-402.

Bachelard, Gastón. 1957. La poética del espacio. Trad. Ernestina de Champourcin. México: Fondo de Cultura Económica. La poétiquedel'espace. París: Presses Universitaires de France, 1997.

Bataille, Georges. 1988. El erotismo. Trad. Antoni Vicens. Barcelona: Tusquets Editores. L'erotisme. Paris: Les Editions de Minuit, 1957.

Baudrillard, Jean. 1997. De la seducción. Trad. Elena Benarroch. México: Red Editorial Iberoamericana. 
Castells, Ricardo. 2000. Fernando de Rojas and the RenaissanceVision. Phantasm, M elancholy, and Didacticism in Celestina. Pennsylvania: Pennsylvania State University Press.

Cull, John T. 1989. "On Reading Fuentes: Plant, Lore, Sex and Death in Aura”. Chasqui: Revista de Literatura Latinoamericana 18, № 2:18-25.

Dauster, Frank. 1982. "The Wounded Vision: Aura, Zona sagrada, and Cumpleaños", Carlosfuentes: A Critical View. Ed. Brody, Robert y Charles Rossman. Austin, Texas: University of Texas Press. 106-120.

Derrida, Jacques. 1994. Spectres of Marx: The State of the Debt, the Work of M ourning, and the N ew International. Trad. Peggy Kamuf. New York: Routledge.

Durán, Gloria. 1971. "La bruja de Carlos Fuentes". Homenajea Carlos Fuentes: Variaciones interpretativas en torno a su obra. Ed. Giacoman, Helmy F. New York: L.A. Publishing Company.

. 1980. The Archetypes of Carlos Fuentes: From Witch to Androgyne. Hamden, Connecticut: Archon Books.

Fuentes, Carlos. 1983. "On Reading and Writing Myself: How I wrote Aura", World Literature Today: A Literary Q uarterly of the University of O klahoma 57, No 4: 531-539.

. 1990. "Juan Rulfo: el tiempo del mito", Valientemundo nuevo: Epica, utopía y mito en la novela hispanoamericana. Madrid: Mondadori España S.A., 145-168. . 1991. Aura. México: Ediciones Era.

Galaz-Vivar Welden, Alicia. 1990. "Aura y los niveles míticos de la realidad: lo mítico y lo sagrado". A Study of Aura Interpretaciones a la obra de Carlos Fuentes: Un gigantedelasletrashispanoamericanas. Ed. Ana María Hernández de López, Madrid: Ediciones Beramar, 115-20.

García-Núñez, Fernando. 1992. "La poética narrativa de Carlos Fuentes". Bulletin Hispanique (Bordeaux) 94, № 1: 263-91.

Harss, Luis y Barbara Dohmann. 1967. “Carlos Fuentes, or theN ew Heresy”. I nto theM ainstream: Conversationswith Latin American Writers. New York: Harper \& Row, Publishers, 276-309.

Hernández de López, Ana María (Ed.) 1988. La obra de Carlos Fuentes: Una visión M últiple. Madrid: Editorial Pliegos.

Koski, Linda. 1990. "Desire in Narrative: A Study of Aura Interpretaciones a la obra de Carlos Fuentes: Un gigante de las letras hispanoamericanas. Ed. Ana María Hernández de López. Madrid: Ediciones Beramar, 127-135.

Ordiz, Francisco Javier. 1987. El mito en la obra narrativa de Carlos Fuentes. León: Universidad de León.

Ortega, Julio. 1988. “Cristóbal Nonato", Vuelta , vol. 12, No 139 (junio). . 1995. Retrato de Carlos Fuentes. Barcelona: Galaxia Gutemberg. . 2000. "Carlos Fuentes: La tradición de la mancha”. Taller dela escritura (Conversaciones, encuentros, entrevistas). México: Siglo XXI, 392-423.

Otero, José. 1976. "La estética del doble en Aura de Carlos Fuentes". Explicación de textos literarios 2: 181-89. 
Paiewonsky-Conde, Edgar. 1988. "La numerología como principio estructurante en Aura de Fuentes”. Cuadernos de Poética (Santo Domingo, República Dominicana) 6, No 16: 7-28

Saldívar, Samuel G. 1985. “Carlos Fuentes y las figuras fantasmagóricas”. Evolución del personaje femenino en la novela mexicana. Lanham, Md.: University Press of America, 97-148.

Viqueira, Ileana. 1981. “Aura: Estructura mítico-simbólica”, Revista de Estudios H ispánicos 8: 25-33.

Zeit, Eileen M. 1983-1984. "La muerte: Una nueva aproximación a Aura”. Explicación deTextos Literarios 12, No 2: 79-89.

Min 